where it is seen coursing like an arrow, and descending in a similar manner. At thirty yards many of them are very accurate in hitting their object. The "stabbing" assegai has a short and stouter handle, has a much smaller and narrower blade, and is attached to the handle by a continuation of the blade in the form of a steel shaft for about half a foot, and there securely fastened. In stabbing they keep the edge very low, making numerous cuts, stabs, and dashes therewith as they approach ; suddenly raising the point, they make a direct stab, and, without withdrawing, a rip. It appears to be a thoroughly methodical operation, requiring considerable skill to acquire. It is an error often made to think that, on nearing an enemy, they all, at a certain signal, bend the handles of their long assegais on their knees, and break them short. I am told this does not take place except when they have no "stabbing," and all "throwing" instruments with them-a circumstance which rarely occurs, as they always keep close to one of the latter as their chief defence.

The wounds, therefore, received from these different proceedings must also differ in character. My late confrère and friend, Surgeon-Major Shepherd, was killed by a thrown assegai just as he was starting from the side of a wounded Natal Carabineer whom he was examining. Trooper Muirhead, of the Carabineers, who was with him at the time, informs me that he saw it coming, bent his head down on his horse's neck, and escaped it. Shepherd was close to him, and received it in his back. He at once fell from his horse with a loud exclamation, and was surrounded by Zulus and finished. The depth a thrown assegai will penetrate is great. In stabbing the abdomen appears to be the target they aim at, if possible. Assegai wounds of the extremities I have met with none-except the case already recorded-of any interest, no important vessel having been injured. One officer of the Contingent received one through the calf of his leg, "pinning him to his saddle"; this healed at once, and he hopped about all the time. I simply kept a bandage upon it.

It will, therefore, be readily conceived that severe and numerous cases of gunshot injuries are not likely to occur in Zulu warfare as far as we are concerned.

If we have to retreat rapidly, then a wounded man means a dead one, as the enemy converts the one into the other at once. Assegai wounds of regions not immediately fatal generally require but the simplest treatment.

Without medicines, lint, bandages, or any of the usual equipment at Helpmakaar, I had to make use of what I could find. A considerable amount of well-tarred tow was found in a box where some wine bottles were packed. This I used as the dressing for all the wounds, and no case did badly. Water or watery lotions were not used, except the former to wash the skin in the neighbourhood of the injuries. A few fibres of the tow were used as drains in the wounds, and appeared to serve the purpose as well as anything else.

\section{NOTE ON CARDIAC THROMBOSIS.}

BY C. E. MACNAMARA, M.C.P.I., \&c., RESIDENT SURGEON, PUBLIC HOSPITAL, GEORGETOWN, BRITISH GUIANA.

A SUBJECT such as cardiac thrombosis needs very little apology in being brought before the members of the medical profession. Undoubtedly it is a condition which is being noticed more every day, and in many late numbers of medical journals cases are to be found reported with particular reference to this condition bearing upon its symptoms and results of such an important nature that any remarks which may be elicited from practitioners who have noticed this sequela of disease will, I have little doubt, be received with that amount of attention which such a subject merits. During a residence of some years in British Guiana, where this disease is of common occurrence, I have had unlimited occasions of watching many of these cases, and, further, have had ample opportunity of verifying in autopsies the previous diagnosis. And now it is with special reference to the appearances of the clots in their distinct stages that I desire to write. As far as my judgment has permitted me to notice I would distinguish two distinct varieties. In the generality of cases where the autopsic condi- tion of the heart is examined, the ordinary post-mortem clot may be noticed, and is characteristic in its appearances, which are most markedly different from the antemortem or fibrinous accumulation of cardiac thrombosis, in which case the fibrine has become distinctly separated from the blood, and forms in the heart, with attachments to the endocardium, a yellowish, soft, frangible mass of a smooth, shining, and translucent appearance, much like strong or firm chicken jelly, tapering away and deepening in colour in the direction of the blood stream, till, for the last few lines of its extent, it bears all the appearance of the post-mortem coagulation. This clot is, in many cases, rapidly formed, easily diagnosed, and, if the disease be amenable to treatment, it is so, I consider, up to this stage ; but my experience does not lead me to think that beyond this period of formation treatment can claim many conquests. The danger of enbolism is, I consider, greatest at this period. Bearing in mind the next, or second stage, this clot, as to its development, may be considered the recent clot, and if the painful effort for life be continued sufficiently long, the causes of thrombosis accompanying it, this clot, in periods varying from twenty to fifty hours, passes into its second stage (the limits of time are conjectural). It is then a white, tough, and smooth shining mass, in size and consistence markedly resembling a small oyster; it is firmly attached to the endocardium, and is frequently found partly obstructing some of the gateways of the heart. In comparison to the recent clot, it is much smaller in size. The patient at this stage may be comparatively easier. The thrombic sounds have increased in harshness, somewhat simulating bad valvular obstruction. The diagnosis is difficult, and in my opinion this clot, when once fairly formed, is most, if not entirely, unfavourable in its issue, and in reference to the first stage, which I have alluded to, I look upon this as the mature clot.

Further stages I have not yet noticed in practice. A description of such, together with the entire clinical teaching of this distressing, though not hopeless, condition, may be found in some of the recent manuals of the Practice of Physic, though it is to be regretted that many able writers have not touched upon this important subject.

\section{NOTES OF CASES OF SPINAL DISEASE TREATED BY DR. SAYRE'S METHOD.}

\section{BY LEIGHTON KESTEVEN, M.R.C.S.}

CASE 1.-L. W-, aged eleven years, was brought to me on account of her having, from early infancy, suffered. from weakness of the muscular system and defective coordination of the muscles of the extremities. In intellect she was as backward as a child five or six years of age. For the last two or three years she has been subject to seizures of petit mal. When I first saw her she was seated in a chair "all of a heap," her head falling on to her shoulders, moving by jerks. Articulation was imperfect. In attempting to speak the muscles of the face were irregularly drawn. The effort to walk, even when supported, evinced her powerlessness to put her heels to the ground. Her movements resembled those of the advanced stage of locomotor ataxy. In using her upper extremities, as for feeding, the muscular jerks would send things flying from her hands. Her general health was fairly good, although she was rather thin. There was no disease of the vertebræ detectable, but the normal curves of the spine were wanting; any curvature might be given according with change of posture. Being of opinion that this feeble condition of the muscular system might be in a great measure owing to irregular compression of the spinal cord, I decided to extend the column by Sayre's method of treatment. The child was suspended, and a plaster-of-Paris jacket applied. Bromide of potassium and bark were administered. The epileptic attacks almost immediately ceased, and during nine months she had only three seizures. Her general physical condition has greatly improved. Locomotion is now possible for short distances, and her upper extremities are under control. She is able to hold up her head, and her articulation has improved. The jacket has been twice re-applied, and is still worn. The improvement in this case may, I think, be fairly attributed 
to the nse of the plaster-of-Paris jacket; the beneficial treatment of the epileptic seizures by the bromide has, doubtless, contributed to the result.

GASE 2.-C. B-C, aged ten years, imbecile and helpless, was in much the same condition from birth as the preceding case. He suffered from severe and frequent attaeks of epilepsy. The jacket was applied five month ago (November, 1878), and bromide of potassium was ad ministered in full doses. The fits have ceased and muscular power has increased. He looks brighter and is more intelligent. The jacket has been reapplied thrice, each time with more and more comfort.

These two cases show that great relief may be afforded under this plan of treatment to cases in which the application would not seem to be specially indicated. The mere mechanical support would seem to have been beneficial, and would doubtless prove so in many instances in which there is no actual disease of the vertebræ.

CASE 3. - In a third case, where caries of the bodies of vertebræ exists, as exhibited in extensive psoas abscess with profuse discharge of pus and hectic fever, great relief and comfort has been afforded by the use of the jacket and the internal administration of steel and quinine.

These cases are not "picked cases," but have occurred to me in series. In bringing them forward I desire to show the wide use to which the method of Professor Sayre may be extended. These are, I believe, the first instances of the employment of this plan in New Zealand. They have been accomplished under difficulties, since I have had to be my own instrument-maker for all the apparatus, even to the construetion of the compound pulleys.

Wellington, New Zealand.

\section{AN IMPERFECTLY DEVELOPED UTERUS.}

$$
\text { BY H. R. OSWALD, M.B., C.M. EDIN. }
$$

C. $\mathrm{T}-$, a servant girl, aged sixteen, came under my care, at Redhill Cottage Hospital, on February 27th, 1879, complaining of a strongly-smelling discharge from the vulva, which had lasted a considerable time, and was most disagreeahle to everyone living in the house with her. The diseharge was accompanied by headaches and pains in the back. On approaching the patient there could be no mis. take about the odour, the whole ward being permeated by it. Her appearance, however, was not unhealthy, nor did she seem like a person suffering from any exhausting drain on the system. On making an inquiry into her personal history, no admission concerning venereal disease was forth coming; and no family history of syphilis could be obtained. The discharge first appeared with her earliest menstrual period.

An examination of the abdomen revealed nothing abnor mal. The examination per vaginam showed there was no hymenial obstruction, though the hymen existed. The index-finger was admitted to half its length. At the top of the vauina the finger seemed to bury itself in a pouch, and no distinct os or cervix uteri could be felt. There was no swelling or redness of the labia, nor were there any signs of inflammation palpable to the finger internally. But an aperture could be distinctly felt at the fundus of the vagina, with two smaller ones at each side of it Bimanual examination per vaginam detected nothing in the shape of a uterus. The speculum revealed the existence of the apertures already mentioned. On the end of the speculum a dirty, almost purulènt-looking, but not copious discharge collected. This discharge was most offensive. A probe could be passed, though only for a short distance, through the central opening. There was no appearance of inflammatory action anywhere. The discharge was sufficiently great to necessitate a change of three or four napkins daily.

Under these circumstances $I$ felt justified in concluding that the uterus was abortive. I was, however, by no means certain of the pathology of the discharge.

The following was my method of treatment of the case. Baths were ordered to be used every day. On the 3rd March and following days the vagina was washed out twice daily with a solution of potassa permanganas by means of Hig. ginson's syringe. Tincture of steel and infusion of quassia were prescribed. As there seemed to be a good deal of foul smell in the urine, I tested it on March 5th, with the fol. lowing result : sp. gr. 1030, neutral, no albumen, no sugar; odour offensive, owing to an admixture of the discharge, which collected at the bottom of the vessel. Suspecting the possibility of vesical mischief, I injected the bladder with a solution of carbolic acid ( 1 to 100 ), but the fluid returned perfectly clear. There was moreover no vesical pain. 'On the 9th March menstruation commenced, and was quite natural. The baths and injections were discontinued, but the patient still took the steel mixture. The offensive discharge did not smell so strong now as formerly. On the 15th menstruation ceased, and all the symptoms recurred in full force. On the 18th, iodide of potassium was administered in place of iron, the baths and injections being resumed. No improvement occurring, the patient was dismissed on the 23rd March, in statu quo, and sent for examination to Dr. Matthews Duncan. Dr. Duncan elicited the following additional important facts:- That, after purging, in the region of the uterus there is to be distinotly felt a mass which, on examination per rectum, might pass for the uterus, but that it feels more rounded and somewhat less mobile than might be expected in a healthy uterus. The probe apparently passes through one of the apertures into a natural channel. Bimannal examination per rectum discovers, on the left side of the pelris and occupying the greater part of it, a tense, elastic swelling, which feels as big as an orange, but is not tender. Dr. Duncan adds that probably one horn of this partially developed organ was distended with dirty, fetid pus.

I have only to add that the patient is still in the same condition, and that I have ordered a change to the seaside. Redhill.

\section{ON A HITHERTO UNNOTED FEATURE OF THE BLOOD IN LEUCOCYTH \#MIA.}

\section{BY E. C. BOUSFIELD, L.R.C.P. LOND., M.R.C.S.}

Much has of late years been discovered and recorded with regard to the appearances of the blood in the above disease, but, so far as I am aware, no reference exists in the work of any author to the feature to which I wish to draw attention. It consists in the presence of irregular granular masses of considerable size, protoplasmic in their nature (as is evident from the fact of their exhibiting faint amoeboid movements), and the somewhat cylindrical shape of the larger ones, suggesting the idea of their having been moulded by the capillaries. The specimen of blood was obtained, as usual, by pricking a cleanly wiped finger. These masses do not exist in every case, for I had under observation at the same time two leukrmic patients, and the differences were so remarkable that it is worth while to briefly describe them.

In the first, that of a female, the splenic tumour was of very considerable size, reaching into the left inguinal region ; she was, however, well nourished, and her blood presented a considerably increased proportion of leucocytes, which were greatly above the normal size. In the second case, that of a male aged about fifty, the splenic tumour was much smaller, the patient remarkably cachectic in appearance, and in the blood were seen not only the protoplasmic masses above referred to, but a considerably increased proportion of leucocytes, of little larger size than the red corpuscles.

What may be the origin of the masses it is not easy to determine. It is not, however, improbable that they are formed by a process analogous to that which Dr. Klein has described as taking place in miliary tuberculosis in lymphatic glands, where, by repeated proliferation of one cell without division, or by the fusion of several smaller ones, a large multinucleated mass of protoplasm is formed; and the inference is strengthened by the close affinity between lymph-corpuscles and leucocytes. There is also the fact that in the patients in whom this condition of blood has existed there has coexisted with it marked cachexia, and this again would indicate a low condition of the vital functions, which might account for the non-fulfilment of the usual process of cell.division. 